$\mathbb{T}$ periodica polytechnica

\author{
Transportation Engineering \\ $4 0 / 2 ( 2 0 1 2 ) \longdiv { 9 5 }, 98$ \\ doi: 10.3311/pp.tr.2012-2.09 \\ web: http://www.pp.bme.hu/tr \\ (c) Periodica Polytechnica 2012
}

RESEARCH ARTICLE

\section{Statistical analysis of the road vehicle fleet of Hungary from environmental aspects}

\author{
Gábor Szendrő / Mária Csete / Ádám Török
}

Received 2012-09-27

\begin{abstract}
The energy problem plays an important role in sustainable development, climate change, adaptation and mitigation of pollution. Considering mitigation the transport sector is a major source of $\mathrm{CO}_{2}$ emissions and other environmental pollutions. These emissions are constantly growing, necessitating alleviation and the increase in efficiency in this area. This study highlights a special theme of this current topic. The aim of this paper is to investigate the environmental trends of the Hungarian vehicle fleet between 2000 and 2010 in comparison with fossil fuel prices.
\end{abstract}

\section{Keywords}

vehicle fleet $\cdot$ mitigation $\cdot$ environmental pollution $\cdot$ statistical analysis

\section{Acknowledgement}

This paper was supported by the János Bolyai Research Scholarship of the Hungarian Academy of Sciences.

\section{Gábor Szendrö}

Department of Environmental Economics, BME, Magyar tudósok krt. 2., H-1111Budapest, Hungary

e-mail: szendro@eik.bme.hu

\section{Mária Csete}

Department of Environmental Economics, BME, Magyar tudósok krt. 2., H-1111 Budapest, Hungary

e-mail: csete@eik.bme.hu

\section{Ádám Török}

Department of Transport Technology and Economics, BME, Sztoczek J. u. 2, H-1111 Budapest, Hungary

e-mail: atorok@kgazd.bme.hu

\section{Introduction}

Social and economic considerations play a key role in changes of the natural environment (and therefore climate change). The increasing frequency of impacts related to climate change have urged detailed analysis of the subject, much like GHG emissions, preparing for changes, preventing adverse effects and minimizing damage [16]. According to the Intergovernmental Panel on Climate Change (IPCC) it can be stated that the anthropogenic greenhouse gas emissions will continue to drive change in the future [8-10, 20]. Hungary committed itself to maximizing greenhouse gas growth at 10\% by 2020 compared to 2005 levels in the non-EU ETS (Emission Trade System) sectors [6. 16]. Several examinations are dealing with energy and climate policy on a global level [1, 2, 4, 7, 11, 12, 19] but only limited research papers consider Eastern Europe predominantly focusing on special fields as the environmental related statistical analysis of road vehicles. Transport needs to be sufficient within the space defined by social, economic and environmental factors so as to satisfy the mobility needs of society in an economically efficient and environment-friendly way [13, 17]. Transport is a major source of $\mathrm{CO}_{2}$ emissions, which, as opposed to industry, is constantly growing, making conservation and increasing efficiency in this area particularly important. Accounting for $10 \%$ of GDP, as well as for 10 million workers, it is also a major source of pollution and noise emissions. The adverse effects of transport are amplified by congestion, resulting in traffic jams, aggravation for motorists and even more pollution [15]. The characteristics of the transport system are especially interesting in the urbanized areas. The Leipzig Charter on Sustainable Cities and the Territorial Agenda of the European Union highlighted the role of local strategies, urban policy and planning tools in contributing to sustainable urban development [5]. Among the five main problems identified in the Charter one is related to transportation that also plays a pivotal role in the urban quality of life [14]. The explosion in scientific and technical development seen in the last century has provided humanity with such tools and technical solutions, which multiply the impacts of influencing the environment exceedingly. Satisfying the growing needs for consumption inevitably damages the environ- 
ment (see Fig. 1]) while the decrease of environmental pollution is a fundamental prerequisite of survival [3, 18].

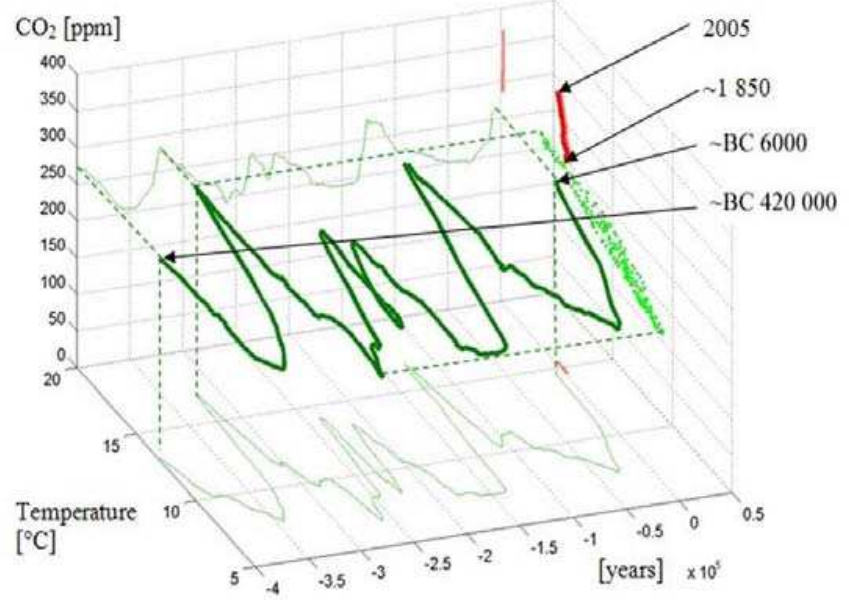

Fig. 1. Complex time series of average atmospheric $\mathrm{CO}_{2}$ concentration and average mean temperature on Earth (source: [17])

\section{Methodology}

The aim of the present paper is to statistically analyse and determine the trends characteristic of the Hungarian vehicle fleet participating in road transport. The analysis of time series data on the different vehicle types and changes in the vehicle stock composition provide valuable data input for strategies and the implementation of a successful transport policy. As we endeavoured to statistically investigate the Hungarian vehicle fleet in the period between 2000 and 2010 with special emphasis on emissions, we examined the environmental classes, age and type of engine of the vehicles. The basis of the investigation was the annual database of Hungarian vehicle fleet between 2000-2010. A meta database has been created by the authors to analyse the trends of Hungarian vehicle fleet. The total vehicle fleet horizontally (buses, trucks, passenger cars) was analysed.

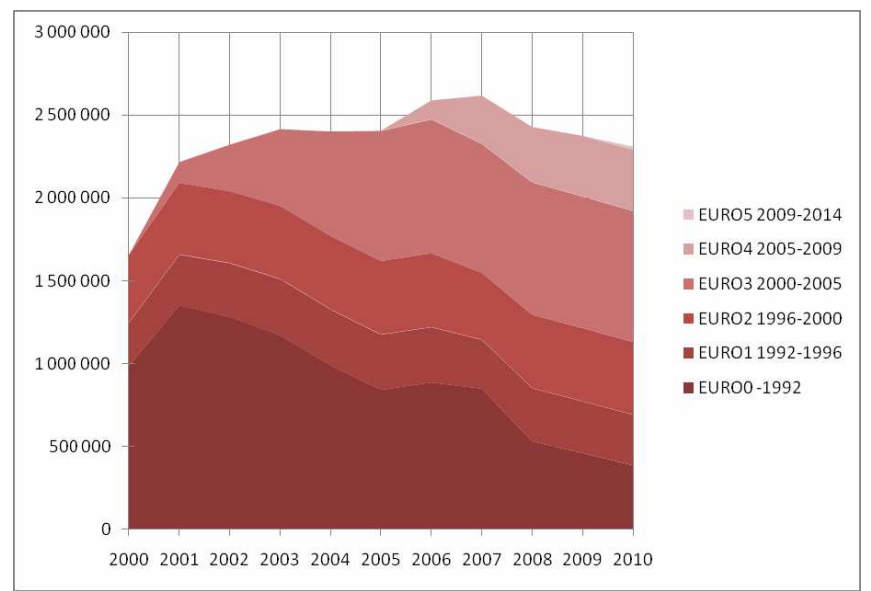

Fig. 2. Gasoline driven passenger cars (source: own research)

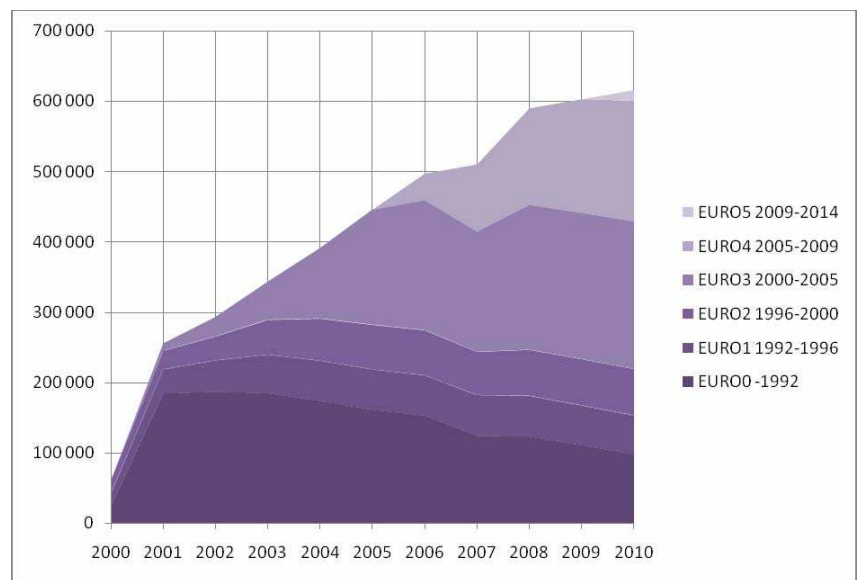

Fig. 3. Diesel oil driven passenger cars (source: own research)

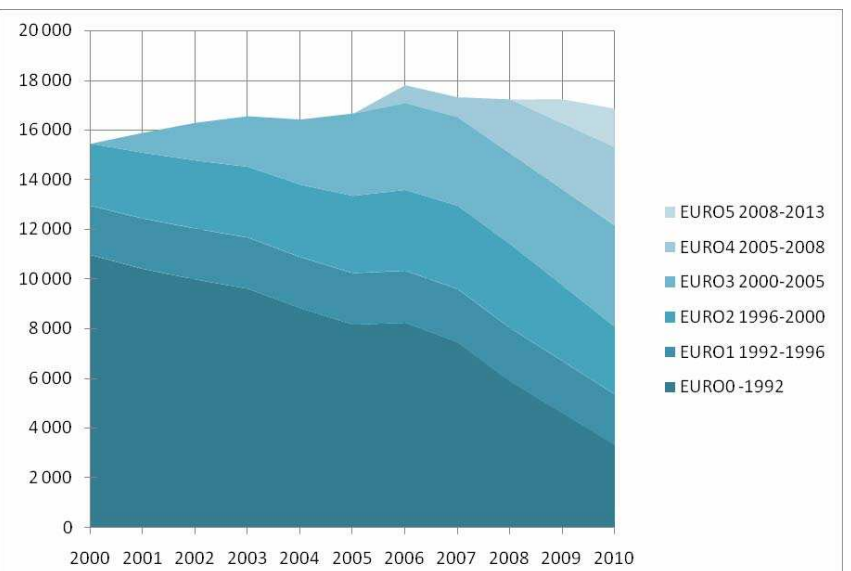

Fig. 4. Diesel oil driven HGVs (source: own research)

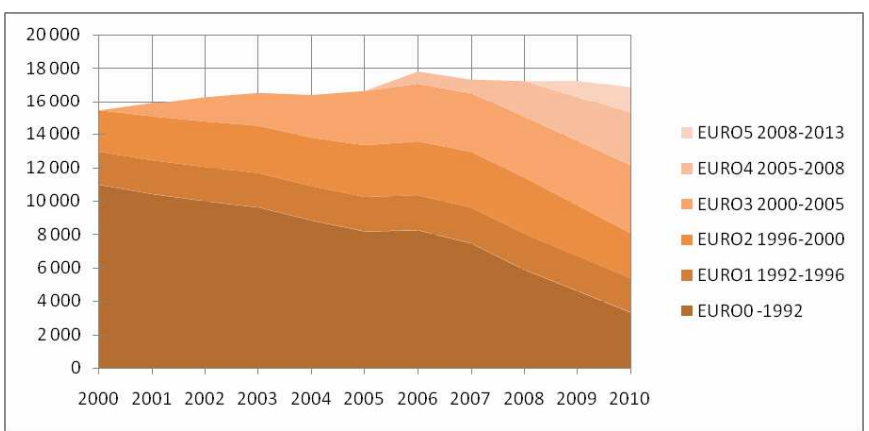

Fig. 5. Diesel oil driven buses (source: own research)

\section{Results}

The following graphs have been calculated using our metadatabase. The graphs are dealing with gasoline driven passenger cars, diesel oil driven passenger cars, diesel oil driven HGVs and diesel oil driven buses. As the data clearly show, due to the economic crisis and increasing price of gasoline, the number of gasoline driven cars is decreasing (see Fig. 2]).

It is also important to note that a considerable part of the vehicle stock is still comprised of vehicles that only meet the EURO 0 standards, giving clear evidence that the vehicle stock of Hungary is quite outdated and it takes a long time for it to be renewed (the average age of the vehicles is too high). 
Fig. 6. Gasoline consumption and price (source: own research)

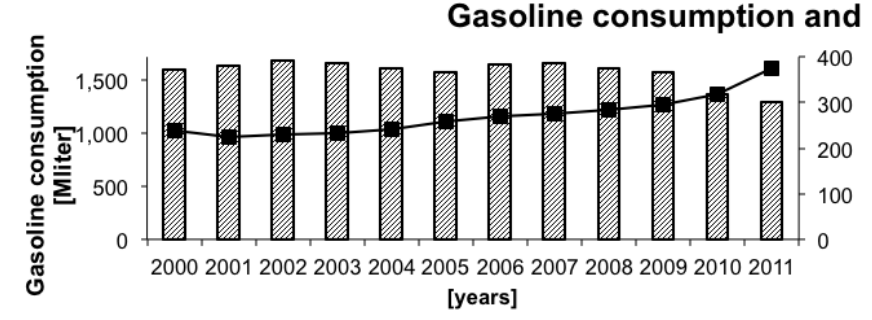

Fig. 7. Diesel oil consumption and price (source: own research)

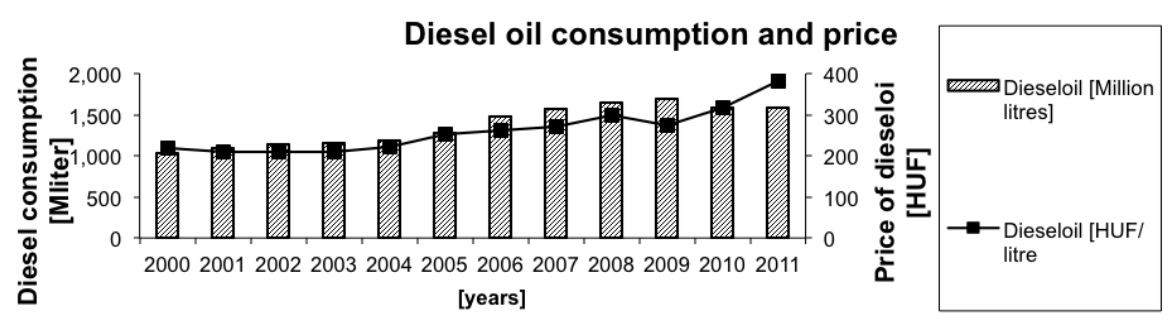

Due to the relatively cheap diesel oil and increasing technological safety of diesel motors - similar to the international trends - in Hungary diesel motors are gaining a significant market share (see Fig. 3).

This is also clear from fuel sales statistics where diesel oil has traditionally been far less significant, but has been gaining ground continuously in the past decade. More recent changes in taxation are likely to halt this process, however, as they have made diesel less advantageous. Another interesting point of this graph is the lack of a clear trend reversal in the number of vehicles as a result of the crisis.

Due to international freight traffic, the average age of $\mathrm{HGVs}$ in Hungary has been decreasing significantly, and the number of vehicles that complied with older EURO standards has been dropping sharply since 2007 (see Fig. 4).

As the figure above shows clearly, the number of HGVs was slightly increasing until 2007 and has been slightly declining since then.

The number of buses is nearly constant and due to the international traffic, the situation is similar as in the case of HGVs the average age of buses in Hungary is decreasing significantly, although EURO 1 and 2 buses are still present in a significant number (see Fig. 5). Further changes in this area are expected as a result of the reorganization of the regional bus operators of Hungary.

\section{Analysis}

The following charts will deal with the consumption and price swings of gasoline and diesel in Hungary. The effects of the crisis and rising fuel prices are especially visible in these areas.

The price of gasoline has been increasing continuously, in line with the international trends (although it should be mentioned that Hungary has now the highest VAT in Europe at 27\%, and the tax included in the price of gasoline is quite high). Since 2008 , the volume of purchased gasoline has been decreasing.
This is in part the consequence of rising oil prices, as well as the result of the crisis, whereas new vehicle sales have come to a standstill, and many vehicle owners with unpaid debts had their vehicles claimed by their creditors.

The price of diesel oil has been increasing continuously, same as gasoline, but then came to a halt in 2008. The reasons for this change are largely similar to the case of gasoline, and the way forward is as yet unclear.

\section{Summary}

Analysing the statistical data of the Hungarian vehicle fleet participating in road transport between 2000 and 2010, it can be concluded that the vehicle fleet is getting slightly younger and - in line with international tendencies - the share of compression engine vehicles is gradually increasing due to the modernisation of these engines (and them being more favourable from an economic point of view). 2001 saw a vital expansion in the vehicle fleet, but unfortunately cheaper vehicles aged between 9-18 years were also put into circulation. A minor decrease in the number of ignition engine vehicles from before 1990 can be witnessed in 2002 and 2003. In 2005 a further drop in the number of older, ignition engine vehicles can be observed, while the vehicle fleet is getting younger in a significantly quicker rhythm regarding the compression engine vehicles, due to a number of young, 4-5 years old compression engine vehicles being put into circulation. In 2006 the aging of the ignition engine vehicle fleet and an essential increase in the number of 22-27 year old vehicles can be witnessed. The change in the age of the vehicle fleet is slight in 2007. Finally 2008 saw the vehicle fleet getting younger due to the drop in the number of ignition engine vehicles manufactured before 1990. Changes in the environment (and within that the climate) and the human actions influencing these are related to the society and economy. Transport needs to be sufficient within the space defined by social, economic and environmental factors so as to satisfy the mobility needs of 
society in an economically efficient and environment-friendly way. The explosion in scientific and technical development seen in the last century has provided humanity with such tools and technical solutions which multiply the impacts of influencing the environment exceedingly. Satisfying the growing needs for consumption inevitably damages the environment while the decrease of environmental pollution is a fundamental prerequisite of survival.

\section{References}

1 Bassi A., Evaluating the use of an integrated approach to support energy and climate policy formulation and evaluation, Energies, posted on 2010, no. 3, 1604-1621, DOI 10.3390/en3091604, (to appear in print).

2 BlesI M, Kober T, Bruchof D, Kuder R, Effects of climate and energy policy related measures and targets on the future structure of the European energy system in 2020 and beyond, Energy Policy 201038 (2010), 62786292, DOI 10.1016/j.enpol.2010.06.018.

3 Bokor Z, Calculation model for transport costing, Periodica Polytechnica Transportation Engineering 39 (2011), 43-47, DOI 10.3311/pp.tr.2011-1.08.

4 Bosetti V, Carraro C, Massetti E, Sgobbi A, Tavoni M, Optimal energy investment and REDD strategies to stabilize atmospheric greenhouse gas concentrations, Resour. Energy Econ., posted on 2009, no. 31, 123-137, DOI 10.1016/j.reseneeco.2009.01.001, (to appear in print).

5 Csete M, Horvath L, Sustainability and green development in urban policies and strategies, Applied Ecology and Environmental Research 10 (2012), no. 2, 185-194.

6 Energy infrastructure priorities for 2020 and beyond - A Blueprint for an integrated European energy network, COM(2010) 677 final, Brussels, November 17, 2010.

7 Folster S, Nystrom J, Climate policy to defeat the green paradox, Ambio, posted on 2010, no. 39, 223-235, DOI 10.1007/s13280-010-0030-7, (to appear in print).

8 Houghton J, Ding Y, Griggs D, Noguer M, van der Linden P, Da X, Maskell K, Johnson C (eds.), Climate Change 2001: The Scientific Basis, Cambridge University Press, Cambridge, 2001.

9 Intergovernmental Panel on Climate Change, Fourth Assessment Report, 2007, http://www.ipcc.ch/

10 Intergovernmental Panel on Climate Change, Third Assessment Report, 2001, http://www.ipcc.ch/

11 Knopf B, Edenhofer O, Flachsland C, Kok M., Lotze-Campen H, Luderer G, Popp A, Managing the low-carbon transition - from model results to policies, Energy J. (2010), no. 31, 223-245.

12 Leimbach M., Bauer N., Baumstark L., Edenhofer O., Mitigation costs in a globalized world: Climate policy analysis with REMIND-R, Environ. Model. Assess., posted on 2010, no. 15, 155-173, DOI 10.1007/s10666-0099204-8., (to appear in print).

13 Markovits-Somogyi R, Data envelopment analysis and its key variants utilized in the transport sector, Periodica Polytechnica Transportatio Engineering 39 (2011), no. 2, 63-68, DOI 10.3311/pp.tr.2011-2.03.

14 Nijkamp P, Perrels A, Sustainable Cities in Europe, Earthscan, LondonSterling, VA, 2009.

15 Szendro G, Congestion charging in Budapest - a comparison with existing systems, Periodica Polytechnica Transportation Engineering 39 (2011), no. 2, 99-103, DOI 10.3311/pp.tr.2011-2.09.

16 Szlavik J, Csete M, Climate and energy policy in Hungary, Energies 5 (2012), no. 2, 494-517, DOI 10.3390/en5020494.

17 Tanczos L, Torok A, The linkage of climate change and energy consumption of Hungary in the road transportation sector, Transport 22 (2007), no. 2, 134-138.

18 Torok A, Climatic Costs of The Road Transport Sector (In Hungarian:
Közúti Közlekedési Szektor Klimatikus Költségei), Közlekedéstudományi Szemle (2008), no. 4, 28-30.

19 Waldhoff S. T., Fawcett A. A., Can developed economies combat dangerous anthropogenic climate change without near-term reductions from developing economies?, Clim. Change, posted on 2011, no. 107, 635-541, DOI 10.1007/s10584-011-0132-7, (to appear in print).

20 Global climate trends 2005, http://earthtrends.wri.org/pdf_ library/data_tables/cli5_2005.pdf 